\title{
Oxidative Stress and Musculoskeletal Pain in University Students with Generalized Joint Hypermobility: A Case-Control Study
}

\author{
Ahmad H Alghadir' \\ Sami A Gabr (iD) ${ }^{1,2}$ \\ Muaz Al-Ghadir 3 \\ 'Rehabilitation Research Chair, College \\ of Applied Medical Sciences, King Saud \\ University, Riyadh, Kingdom of Saudi \\ Arabia; ${ }^{2}$ Department of Anatomy, Faculty \\ of Medicine, Mansoura University, \\ Mansoura, Egypt; ${ }^{3}$ Department of \\ Orthopedics, King Fahad Medical City, \\ Riyadh, Kingdom of Saudi Arabia
}

Objective: The current case-control study aimed to evaluate generalized joint hypermobility $(\mathrm{GJH})$ and its association with pain intensity, cellular oxidative stress, and collagenassociated disorders in university students aged 18-25 years old.

Background: Joint hypermobility has been recognized in healthy subjects and people who are carriers of cellular disorders in connective tissues. Cellular tissue oxidative stress and collagen-associated disorders were shown to be associated with joint hypermobility (JH).

Materials and Methods: A total of 300 university students aged 18-25 years were randomly invited from different medical and science faculties in Mansoura university, Mansoura, Egypt to participate in this case-control study. Only 280 university students who had no exclusion criteria like chronic health problems, physical disability, musculoskeletal disorders, and body mass index (BMI) of $\geq 25$ underwent an initial clinical interview and Beighton scoring as measures of GJH. Pain intensity, physical activity, oxidative stress parameters; TAC, TOC, OSI, and collagen-associated parameters; cellular prolidase activity and hydroxyproline were evaluated by using a prevalidated questionnaire, colorimetric, and immunoassay techniques.

Results: GJH was significantly reported in $57.1 \%$ of the study population, and most of them are females. Compared to men, females with GJH showed poor physical activity, lower TAC, and significantly higher levels of TOC, OSI, cellular prolidase activity, and hydroxyproline. Based on our findings, a high Beighton score is closely related to the tissue levels of prolidase, hydroxyproline, antioxidant activity, pain intensity, and poor physical activity in the female with GJH compared to men.

Conclusion: GJH was significantly reported in $57.1 \%$ of the study population, and most of them are females. The incidence of GJH showed to be associated with poor physical activity, abnormal cellular oxidative stress, and collagen abnormalities measured by significant increase in change in cellular prolidase activity and hydroxyproline.

Keywords: generalized joint hypermobility, prolidase activity, hydroxyproline, oxidative stress

\section{Introduction}

Hypermobility, clinically defined as a wider range of movements in one or more joints with certain physiological disorders. ${ }^{1-6}$ In addition to healthy people, hypermobility frequently is observed mostly among acrobats, gymnasts, and ballerinas. ${ }^{1-5}$ Demographic factors are shown to be associated with the severity and incidence of hypermobility. Age, gender, ethnicity, physical activity, sports, and athletic abilities were
Rehabilitation Research Chair, College of Applied Medical Sciences, King Saud University, Riyadh, Kingdom of Saudi Arabia

Tel +966562060018

Fax +966 I469854I

Email dr.samigabr@gmail.com 
significantly associated with the degree of hypermobility. ${ }^{7-9}$ Some degree of hypermobility $25-50 \%$ was reported among children below 10 years old. ${ }^{7-11}$

Several ranged genetic and systemic diseases were shown to be associated with the incidence of hypermobility. ${ }^{12,13}$ Most of them are Down Syndrome, Osteogenesis imperfecta, Stickler Syndrome, traumas, degenerative joint and bone diseases, muscle weakness, musculoskeletal traits, cardiovascular and nervous system involvements ${ }^{13-15}$ Other pieces of evidence reported that hypermobility syndrome characterized by multisystemic manifestations especially, chronic pain in association with dysfunction in both autonomic and gastrointestinal motility. ${ }^{13-18}$

In addition, the catastrophic effects of hypermobility were the increase in cellular tissue oxidative stress markers. ${ }^{19,20}$ Thus, reactive oxygen species have been implicated in the pathogenesis of many diseases particularly musculoskeletal pain, chronic fatigue, and joint hypermobility. ${ }^{20-22}$

Similarly, collagen-associated disorders were shown to be associated with joint hypermobility syndrome (JHS). ${ }^{22,23}$ Prolidase is one of the most pivotal cytosolic and multifunctional exopeptidases which possesses the unique ability to degrade iminodipeptidase, which releases carboxy-terminal proline or hydroxyproline from oligopeptides, particularly collagen. ${ }^{24}$

Collagen is an important substrate of prolidase due to its high contents of amino acids. Serum prolidase enzyme activity (SPEA) was significantly increased in diseases with chronic inflammation of the tissue and/or increased turnover of collagen such as rheumatic diseases, asthma, and thalassemia. ${ }^{25-27}$ Although collagen-associated disorders are intracellular, no or limited studies to date have investigated prolidase levels or other collagen-related parameters in serum samples in subjects with joint hypermobility. Thus, the aim of this case control study was to evaluate generalized joint hypermobility (GJH) and its association with pain intensity, cellular oxidative stress, and collagen-associated disorders in university students. Furthermore, this study hypothesized that GJH could be associated with physical activity, cellular oxidative stress, and collagen abnormalities measured by cellular prolidase activity and hydroxyproline among university students.

\section{Materials and Methods}

\section{Subjects}

A total of 300 university students aged (18-25 years) were randomly invited from different medical and science faculties in Mansoura university, Mansoura, Egypt to participate in this case control study. Students were invited to participate in this study during the period of October 2017 to March 2018. Only 280 university students who had no exclusion criteria such as any acute or chronic health problems like diabetes, cardiovascular diseases, infections, physical disability, body mass index (BMI) of $\geq 25$, previous/current joint, chronic disease of locomotor system, or musculoskeletal disorders were included in this study. Based on the Beighton score analysis, the subjects were classified into two groups: the control group $(n=120$, BS: $\leq 3 / 9)$ and the GJH group ( $n=160, B S: \geq 4 / 9)$ as shown in the flow diagram (Figure 1). All participants were asked to complete self-administered questionnaires on hypermobility including a valid five-item questionnaire and a survey on multisystemic associations of hypermobility as previously reported in the literature. $^{28,29}$

All protocol steps were prepared according to the ethical guidelines of the 1975 Declaration of Helsinki and then reviewed and approved by the ethical committee of Rehabilitation Research Chair (RRC), King Saud University, Kingdom of Saudi Arabia, under file number ID: RRC-2017-098. All participants were informed the importance of the study and a written informed consent was obtained from them before data collection. Whole blood samples were collected, centrifuged for $1 \mathrm{~min}$ at $1400 \mathrm{rpm}$ and the resulting serum samples were collected and were kept frozen at $20^{\circ} \mathrm{C}$ until reused. The demographic and clinical data of the participants are in Table 1.

\section{Assessment of Joint Hypermobility}

All participants were subjected to evaluate GIH by Beighton score which is internationally validated to estimate GIH in all ages as previously reported. ${ }^{12,23,30}$ A range of motion scale proposed by Beighton et $\mathrm{al}^{31}$ was used to assess joint hypermobility. In this test, hypermobility was identified by examining and signaling the flexibility of five areas of the body through extension of these parts beyond the physiological limits. ${ }^{31}$ Finally, the degree of hypermobility was scored from the range of motion scale where a score of $\geq 4$ is classified as generalized joint hypermobility. Thus, our participants with a Beighton score of $\geq 4 / 9$ were included in the GJH group and those with a score $\leq 3 / 9$ were included in the control group. ${ }^{32}$ 


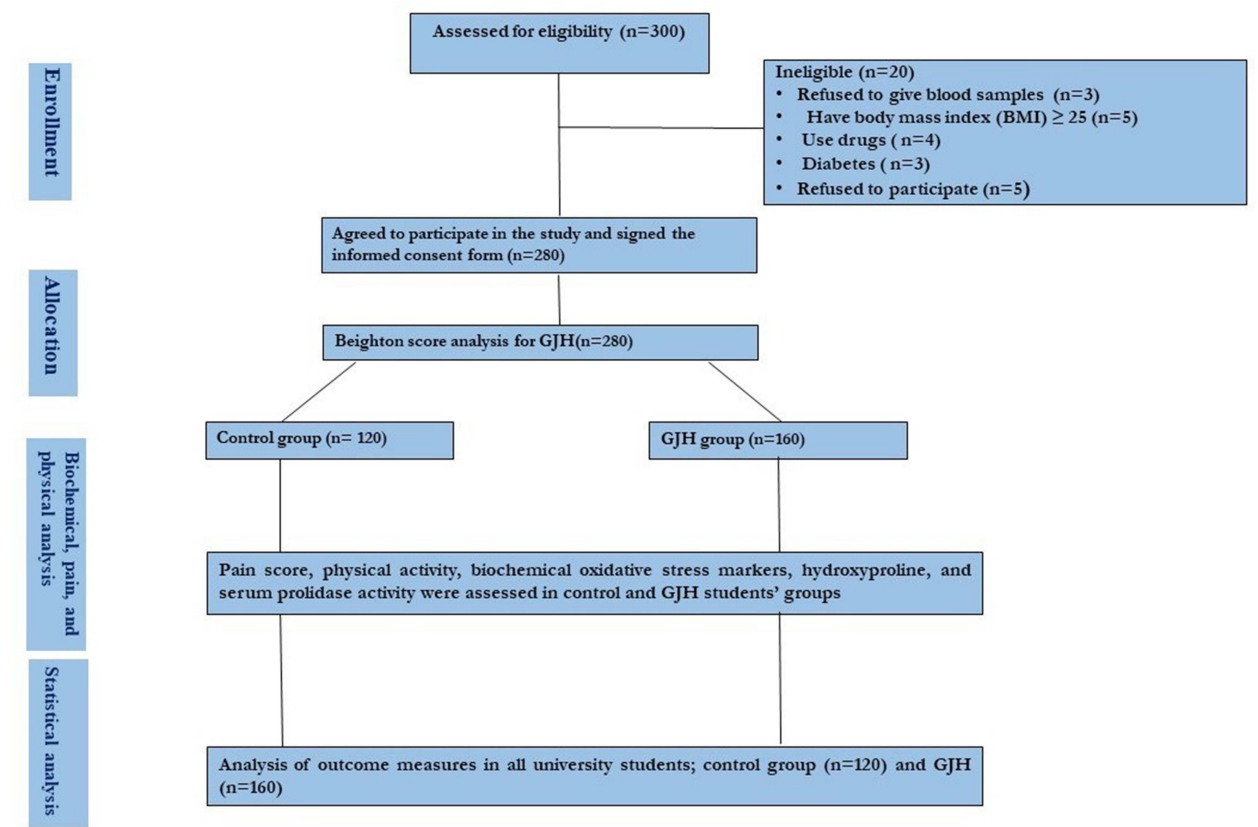

Figure I Outline of GJH screening as well as associated assessments, pain score, physical activity, oxidative stress markers, hydroxyproline, and serum prolidase activity in all university students (control and $\mathrm{GJH}$ ).

\section{Anthropometric Measurements}

Standardized procedures such as a tape measure and calibrated Salter Electronic Scales (Digital Pearson Scale; ADAM Equipment Inc., Columbia, MD, USA) were used to evaluate height and weight of all participants, respectively. ${ }^{33,34}$ In addition, validated universal cutoff values were used to calculate adiposity parameters such as BMI and waist-to-height ratio (WHtR) respectively. ${ }^{33,34}$

\section{Assessment of Pain Score and Physical Activity}

Physical fitness score measured as maximum oxygen uptake (VO2 max) and total energy expenditure (TEE) as previously reported. ${ }^{35-38}$ Total energy expenditure (TEE) was evaluated by calculating basal metabolic rates (BMR) from body mass, height, age, sex, and type of physical activity of all participants using a pre-validated equation as previously reported. ${ }^{35-38}$ A standard $100 \mathrm{~mm}$ visual analog scale (VAS) was used to estimate pain intensity of all participants as previously reported. ${ }^{39,40}$ For all subjects, pain intensity was evaluated by an excellent reliable VAS score which estimate the change in pain intensity as mentioned previously. ${ }^{32,40}$

\section{Assessment of Oxidative Stress Markers}

For all participants, a novel automated measurement method was used to evaluate total antioxidant capacity (TAC) in all serum samples. TAC was estimated in the supernatant fractions of each serum sample as developed previously in the literatures. ${ }^{20}$ In addition, a novel automated measurement method was performed to estimate total oxidant activity (TOA) in all serum samples. The activity of TOA was estimated in the resulting supernatant fractions as mentioned previously. ${ }^{21}$ Oxidative stress index (OSI) was also identified for all subjects. The results of OSI refer to the degree of oxidative stress was calculated as follows:

$\left\{[\right.$ OSI (arbitrary units $\left.\left.)=[\mathrm{TOA} / \mathrm{TAC}] \times 100^{14}\right]\right\}^{20,21}$

\section{Measurement of Hydroxyproline and Serum Prolidase Activity (SPEA)}

In this experiment, a commercially available colorimetric assay kit (Catalog \#K555-100; BioVisionIncorporated, Milpitas, CA, USA) was used to estimate serum hydroxyproline according to manufacturer instructions. ${ }^{41}$ In addition, a commercially immuno assay ELIAS kit (Hangzhou Eastbiopharm Company, Hangzhou, China) was used to identify SPEA in serum samples of all subjects. ${ }^{42}$

\section{Statistical Analysis}

The sample size used in this study was calculated by considering that the prevalence of hypermobility among adolescence with age range $(18-25$ years $)$ was unknown $(p=0.50)$, with a reliability of $96 \%$ and an expected frequency of $8.3 \%$. Thus, a sample of 280 subjects were included in this study. 
Table I Baseline of Clinical and Laboratory Characteristics of the Study Groups

\begin{tabular}{|c|c|c|c|}
\hline Parameters & Control $(n=120 ; 42.9 \% ;$ BS: $\leq 3 / 9)$ & GJH (n=160;57.14\%; BS; $\geq 4 / 90)$ & P-value \\
\hline Age in years & $19.7 \pm 1.6$ & $20.6 \pm 1.7$ & 0.168 \\
\hline Gender (M/F) & $80 / 40$ & $50 / 110$ & 0.13 \\
\hline BMI (kg/m2) & $18.6 \pm 2.3$ & $19.2 \pm 1.9$ & 0.18 \\
\hline Waist $(\mathrm{cm})$ & $79.3 \pm 5.1$ & $82.5 \pm 4.5$ & 0.23 \\
\hline Hips (cm) & $91.5 \pm 2.9$ & $89.8 \pm 3.7$ & 0.42 \\
\hline WHR & $88.9 \pm 2.7$ & $92.7 \pm 0.21$ & 0.81 \\
\hline $\mathrm{WHtR}$ & $0.65 \pm 0.19$ & $0.72 \pm 0.23$ & 0.51 \\
\hline Physical activity (PA): & & & 0.001 \\
\hline $\mathrm{VO}_{2} \max \left(\mathrm{mL} / \mathrm{kg}^{*} \min \right)$ & $36.7 \pm 2.8$ & $28.9 \pm 3.4$ & \\
\hline BMR (kcal/day) & $4.8 \pm 3.1$ & $2.9 \pm 2.7$ & \\
\hline TEE (kcal/day) & $8.2 \pm 6.1$ & $3.8 \pm 2.1$ & \\
\hline PA scores & $6.2 \pm 4.1$ & $3.1 \pm 1.6$ & \\
\hline TBS(0-9) & $2.6(1.5-2.7)$ & $4.9(3.6-6.4)$ & 0.001 \\
\hline Pain intensity & $11.8 \pm 2.8$ & $36.8 \pm 11.7$ & 0.001 \\
\hline
\end{tabular}

Notes: Values are expressed as mean \pm SD; Kruskal-Wallis one-way ANOVA, and post-hoc (Tukey HSD) test were used to compare the mean values of the studied variables. Variables were considered significantly different at $P<0.05$.

Abbreviations: TBS, Total Beighton score; $\mathrm{BMI}$, body mass index; $\mathrm{WHtR}$, waist to height ratio; PA, physical activity; $\mathrm{VO}_{2}$ max, maximal oxygen uptake; $\mathrm{BMR}$, basal metabolic rate (kcal/day); TEE, total energy expenditure (kcal/day); GJH, Generalized joint hypermobility.

Kruskal-Wallis one-way ANOVA, and post-hoc (Tukey HSD) test were used to perform a comparison between the studied variables. Additionally, a one-way analysis of covariance was used to determine whether there were significant differences in the study variables between the study groups. Finally, post hoc pairwise multiple comparisons were performed using Bonferroni correction in order to detect significant differences between two specific groups. The data obtained were deemed significant at $\mathrm{P}<0.05$ (SPSS statistical 13.0 software version for windows; SPSS Inc., Chicago, IL, USA).

\section{Results}

In this study, a total of 280 university students were recruited, including 150 women (53.6\%) and 130 men
(46.4\%), aged 18-25 years (Table 1). GJH was reported in $57.14 \%$ of the study population (TB score: $4.9 \pm 3.6$ ), most of them are females ( $68.75 \%$ vs 31.25 for men). The incidence of GJH showed no associations with adiposity parameters of the studied subjects $(P>0.005)$. Only, physical activity scores measured by $\mathrm{VO}_{2} \mathrm{max}$, BMR, TEE, and pain intensity were shown to be associated with the incidence of GJH among university students. There was a significant $(\mathrm{P}=0.001)$ decrease in physical activity scores with increased $(\mathrm{P}=0.001)$ pain intensity among subjects with GJH compared to healthy controls (Table 1).

Serum prolidase enzyme activity (SPEA) and hydroxyproline as collagen parameters were estimated in this study (Table 2). Serum prolidase enzyme activity $(\mathrm{P}=0.001)$ and hydroxyproline $(\mathrm{P}=0.001)$ were significantly higher in

Table 2 Hydroxproline, Prolidase Activity, and Oxidative-Antioxidative Status in the Study Groups (Control and GJH)

\begin{tabular}{|l|l|l|l|}
\hline Parameters & Control (n=1 20; 42.9\%) & GJH (n=160; 57.1\%) & P-value \\
\hline Hydroxyproline $(\mathrm{ng} / \mathrm{mL})$ & $2.8 \pm 1.3$ & $6.7 \pm 3.4$ & 0.001 \\
SPEA (IU/L) & $165.1 \pm 12$ & $235.8 \pm 45.8$ & $0.00 \mathrm{I}$ \\
TAC $(\mu \mathrm{mol}$ Trolox Eq t/l) & $4.85 \pm 0.86$ & $1.62 \pm 0.87$ & 0.001 \\
TOA $(\mu \mathrm{molH} 2 \mathrm{O} 2 \mathrm{Eq} . / \mathrm{L})$ & $23.8 \pm 11.3$ & $48.5 \pm 15.7$ & $0.00 \mathrm{I}$ \\
OSI $\left(\mathrm{H}_{2} \mathrm{O}_{2} /\right.$ Trolox) & $18.9 \pm 8.6$ & $38.9 \pm 13.5$ & 0.005 \\
\hline
\end{tabular}

Notes: Values are expressed as mean \pm SD; Kruskal-Wallis one-way ANOVA, and post-hoc (Tukey HSD) test were used to compare the mean values of the studied variables. Variables were considered significantly different at $P<0.05$.

Abbreviations: $\mathrm{GJH}$, Generalized joint hypermobility; SPEA, Serum prolidase enzyme activity; TAC, Total antioxidant capacity; TOA, Total oxidant activity; OSI (Arbitrary Unite), Oxidative stress index. 
Table 3 Correlation Between Hypermobility Syndrome (Beighton Score: 0-9) with Serum Hydroxyproline, Serum Prolidase Activity, and Oxidative Stress Parameters in Control and $\mathrm{GJH}$

\begin{tabular}{|c|c|c|c|c|}
\hline \multirow[t]{3}{*}{ Parameters } & \multicolumn{4}{|c|}{ Beighton Score (BG-Score) (0-9) } \\
\hline & \multicolumn{2}{|c|}{$\begin{array}{c}\text { Control } \\
(n=120 ; 42.9 \%) \\
\text { BG- Score }(2.6 \\
\pm 2.7)\end{array}$} & \multicolumn{2}{|c|}{$\begin{array}{c}\text { GJH (n= l60; } \\
\text { 57.I\%) BG-score } \\
(4.9 \pm 3.6)\end{array}$} \\
\hline & $\mathbf{R}$ & $\mathbf{P}$ & $\mathbf{R}$ & $\mathbf{P}$ \\
\hline PA-score & 0.125 & 0.01 & -0.148 & 0.001 \\
\hline Pain intensity & 0.145 & 0.01 & 0.128 & 0.001 \\
\hline Hydroxyproline (ng/mL) & 0.158 & 0.01 & 0.367 & 0.001 \\
\hline SPEA (IU/L) & 0.148 & 0.01 & 0.158 & 0.001 \\
\hline TAC ( $\mu$ mol Trolox Eq t/l) & 0.018 & 0.01 & -0.125 & 0.001 \\
\hline TOA ( $\mu$ molH2O2 Eq./L) & 0.138 & 0.01 & 0.039 & 0.001 \\
\hline OSI $\left(\mathrm{H}_{2} \mathrm{O}_{2} /\right.$ Trolox $)$ & 0.278 & 0.01 & 0.019 & 0.001 \\
\hline
\end{tabular}

Note: Data are R (spearman).

Abbreviations: GJH, Generalized joint hypermobility; SPEA, Serum prolidase enzyme activity; TAC, Total antioxidant capacity; TOA, Total oxidant activity; OS (Arbitrary Unite), Oxidative stress index; BG-score, Beighton score; PA-score, physical activity score.

subjects with GJH compared to normal controls (Table 2). In addition, serum oxidative stress parameters; TAC, TOA, and OSI were evaluated in this study. Serum TOA $(\mathrm{P}=0.001)$,
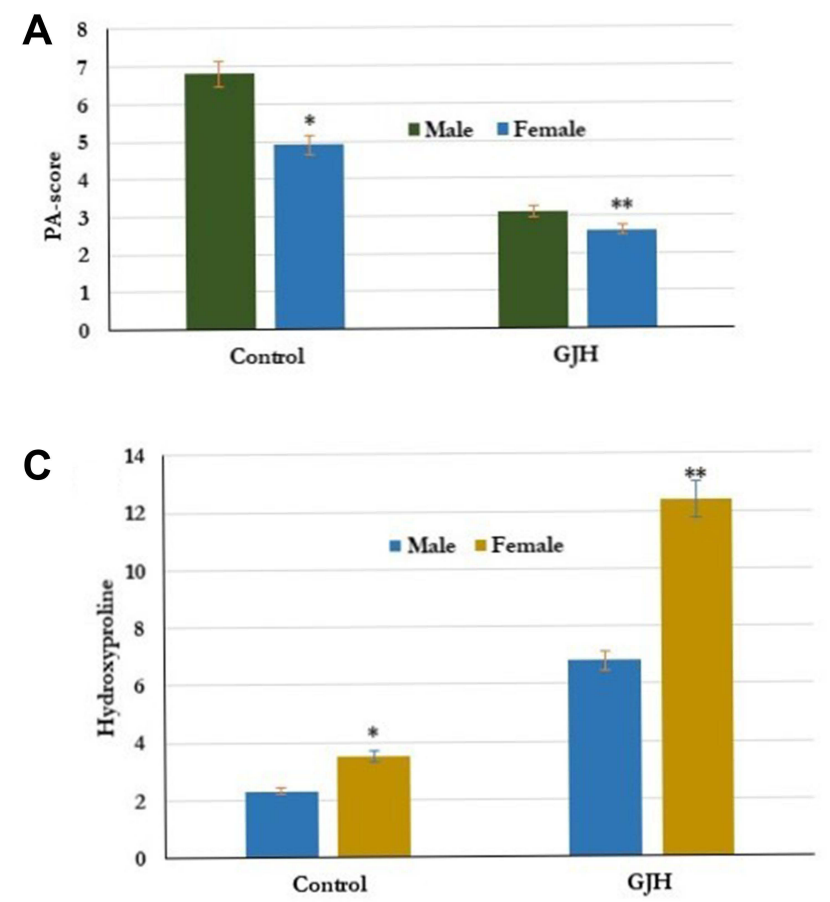

and OSI $(\mathrm{P}=0.005)$ significantly increased, and serum TAC $(\mathrm{P}=0.001)$ significantly decreased in subjects with GJH compared to healthy controls (Table 2).

The incidence of GJH among younger ages is significantly associated with physical activity, pain intensity, collagen deposition (hydroxyproline and SPEA), and oxidative stress (Table 3 ). The incidence of GJH was positively correlated $(\mathrm{P}=0.001)$ with pain intensity, SPEA, hydroxyproline, TOA, OSI, and negatively correlated $(\mathrm{P}=0.001)$ with physical activity, and TAC respectively as in Table 3. Compared to men $(\mathrm{P}=0.001)$, females with GJH showed lower PA, TAC, and higher levels of serum SPEA, hydroxyproline, TOA, OSI, and pain intensity as shown in Figures 2 and 3.

\section{Discussion}

In this study, generalized Joint hypermobility (GJHS) was significantly reported in $57.14 \%$ of the study population (TB score: $4.9 \pm 3.6$ ), most of them are females. However, no association was found in comparison to adiposity markers (BMI, waist, hip, WHR, WhtR).

Similar to our study, the frequency of generalized hypermobility showed to be higher in girls (27.5\%) compared to boys $(10.6 \%)$ using the same threshold of more than 4 points in the Beighton scale. ${ }^{10}$ This study also
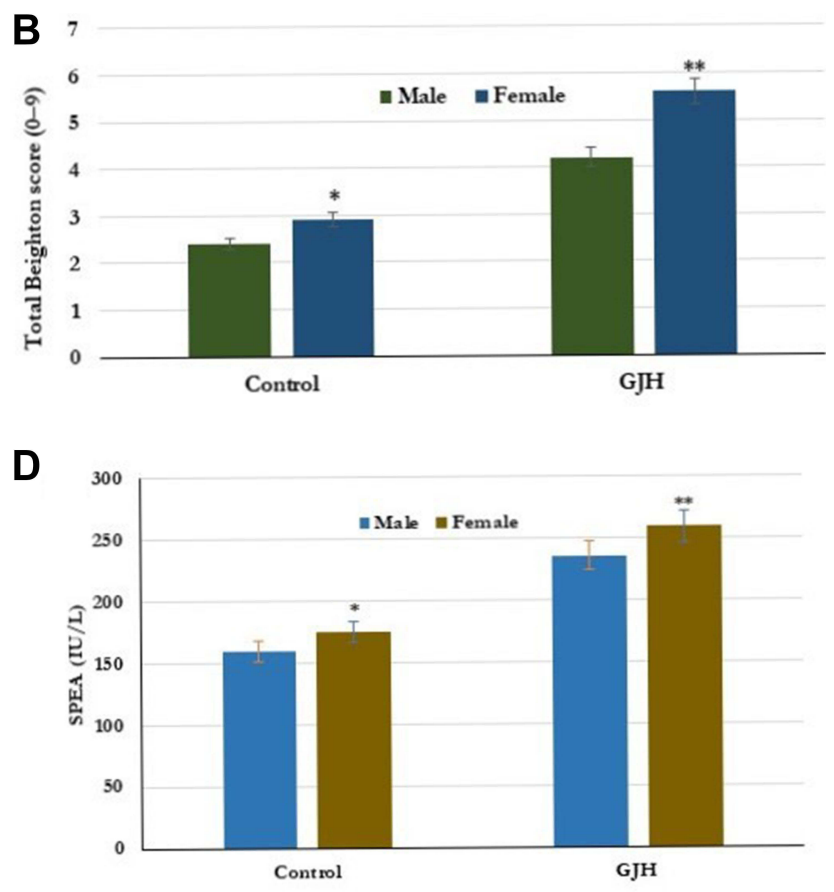

Figure 2 Effect of gender on PA (A), Total Beighton score (0-9) (B), Hydroxyproline (C), and SPEA (IU/L) (D) *p < 0.0 I (KruskaleWalis, Dunn's post hoc test)**p < 0.00I (KruskaleWalis, Dunn's post hoc test). Odds ratios were calculated to measure the relative odds of the occurrence of hypermobility in nine joints given the gender of participants (ie, females to males). The calculated Odds ratios were less than unity, whereas the closer the value to I is related to the lower the risk factor of a specific gender to the occurrence of $\mathrm{GJH}$.

Abbreviations: GJH, Generalized joint hypermobility; SPEA, Serum prolidase enzyme activity; PA-score, physical activity score. 

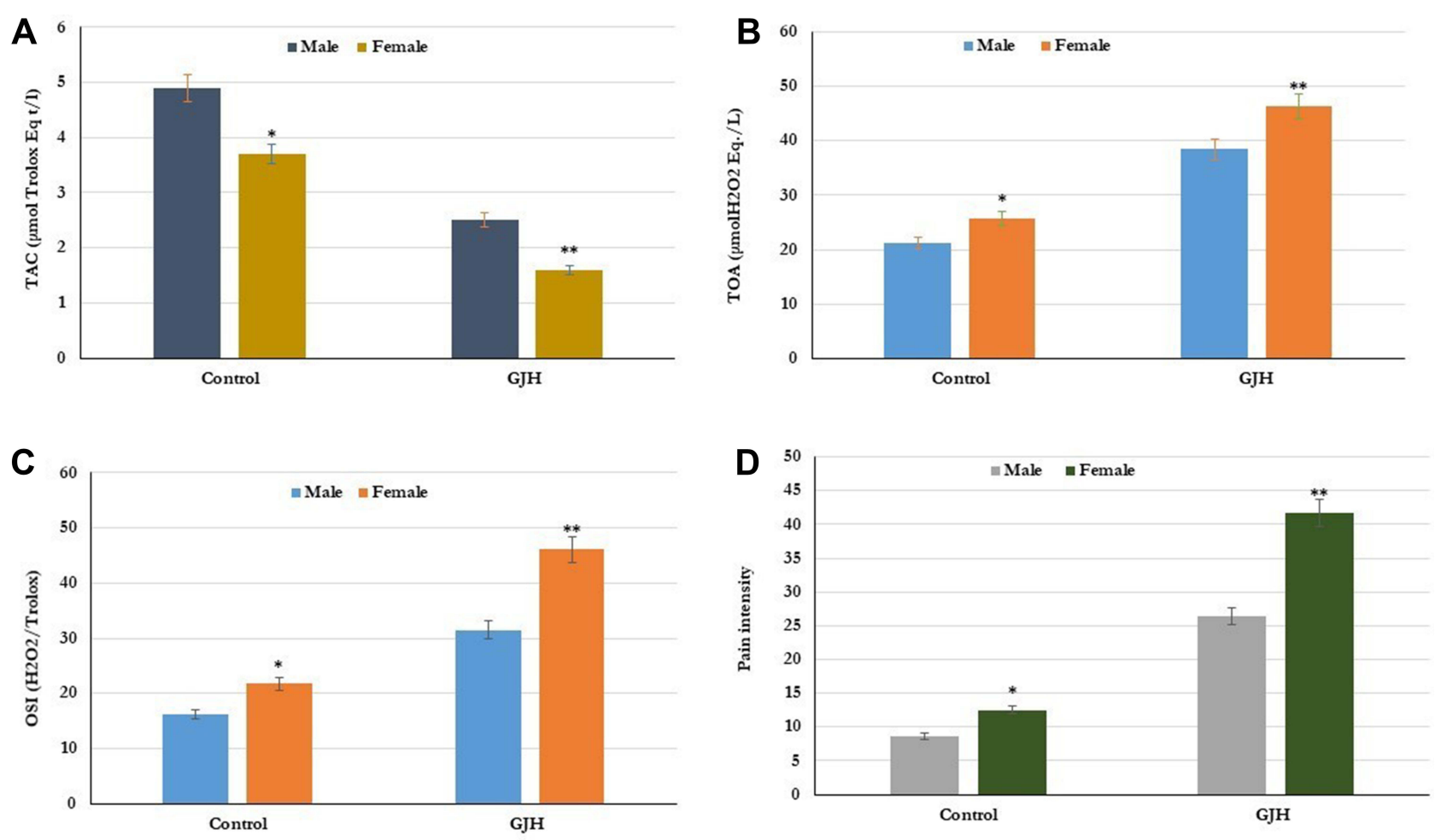

Figure 3 Effect of Gender on oxidative stress; TAC (A), TOA (B), OSI (C), and pain intensity (D) in control $(n=120 ; 42.9 \%)$ and GJHS ( $n=160 ; 57.1 \%)$. ${ }^{*}<0.01 . * * p<0.001$ ManneWhitney test. Odds ratios were calculated to measure the relative odds of the occurrence of hypermobility in nine joints given the gender of participants (ie, females to males). The calculated Odds ratios were less than unity, whereas the closer the value to $I$ is related to the lower the risk factor of a specific gender to the occurrence of $\mathrm{GJH}$.

Abbreviations: GJH, Generalized joint hypermobility; SPEA, Serum prolidase enzyme activity; TAC, Total antioxidant capacity; TOA, Total oxidant activity; OSI (Arbitrary Unite), Oxidative stress index.

supports the absence of any association between hypermobility and adiposity measured by body mass index. ${ }^{10}$ In addition, the prevalence of joint hypermobility was previously studied in a population of university students aged $18-25$ years. ${ }^{43}$ In that study, generalized GJH was significantly reported in $25.9 \%(\mathrm{n}=87)$ of the studied university students using Beighton scoring analysis. Matched to our study, females showd higher GJH (33\%, n=73) compared to males $(12.3, n=14){ }^{43}$ Moreover, the degree of joint hypermobility (13.1\%) and hypermobility spectrum disorders $(12.8 \%)$ were significantly reported in females more than males. ${ }^{43}$

In adult subjects, generalized hypermobility was also described in $50 \%$ of respondents most of them were of girls $(59 \%)$ compared to $(36 \%)$ in adult women, which supports the higher incidence of GJH among female younger ages. ${ }^{44}$ In contrast to our results, localized hypermobility was more frequent in younger ages than generalized hypermobility with low impact or association with the physical and mental component scores as well as the time dedicated to physical activity. ${ }^{45}$
In this study, the incidence of GJH significantly associated with poor physical activity, higher pain intensity. Previous studies showed that hypermobility was significantly associated with the sedentary lifestyle and musculoskeletal pain in adolescents, which is significantly considered as a two-fold increased risk factor among younger ages with hypermobility. ${ }^{46,47}$ It was proposed that the association with generalized joint hypermobility may be due to associated mechanical trauma which exerts pain and cellular muscular injury. ${ }^{48-50}$ In adults with GJH, joint pain and instability as predominant musculoskeletal conditions were frequently associated with GJH. ${ }^{29}$ This may be related to mechanical impact or repeated strain activity. ${ }^{29}$

In human and animal tissues, hydroxyproline and prolidase enzyme play an important role in collagen catabolism and synthesis. ${ }^{25-27,51-53}$ Prolidase activity, as well as hydroxyproline, are altered in fibrotic diseases, inflammatory and chronic pains which are significantly affected by oxidative stress. ${ }^{51,52}$ In physiological and pathophysiological processes, prolidase activity plays a potential role in 
cellular inflammation, angiogenesis, and joint hypermobility. ${ }^{54}$

In the present study, serum prolidase enzyme activity (SPEA; $\mathrm{P}=0.001)$ and hydroxyproline $(\mathrm{P}=0.001)$ were significantly increased in subjects with GJH compared to normal controls. The data showed that the differential expression of SPEAs along with hydroxyproline in patients with JHS is significantly associated with the dysregulation of collagen metabolism. Thus, more stress was exerted in all tissues of patients with JHS than normal controls, exhibiting higher prolidase enzyme activity, higher production of hydroxyproline, and overall dysregulation of collagen metabolism a reduction in the level of collagen. Cellular prolidase activity is essential in the degradation of proline- and hydroxyproline-containing amino peptides at the $\mathrm{C}$ terminus. ${ }^{55}$ Also, it was reported that higher prolidase activity is linked in such a way with an increment in the rate of collagen turnover. ${ }^{56}$ Although JHS is a collagen-associated disorder, a negative correlation between serum prolidase levels and the Beighton score was reported in children with $\mathrm{JHS}^{57}$

The pathogenesis of many diseases, particularly musculoskeletal pain, chronic fatigue, and joint hypermobility, is shown to be associated with the overproduction and initiation of cellular reactive oxygen species (ROS). ${ }^{20-22}$

In this study, TAC, TOC, and OSI were evaluated as measures of oxidative stress in subjects with GJH and healthy controls. Serum TOA $(\mathrm{P}=0.001)$, and OSI $(\mathrm{P}=0.005)$ significantly increased, and serum TAC $(\mathrm{P}=0.001)$ significantly decreased in subjects with GJH compared to healthy controls. Previous studies showed that the catastrophic effects of hypermobility appeared in the increase of cellular tissue oxidative stress markers. ${ }^{19,20}$ Our results suggest a change in the cellular oxidative/antioxidative balance especially in patients with associated joint hypermobility. ${ }^{58,59}$

According to our findings, a high Beighton score is closely related to the tissue levels of prolidase, hydroxyproline, antioxidant activity, pain intensity, and poor physical activity in the female with GJH compared to men. In addition, GJH in female younger ages was significantly associated with collagen abnormalities of collagen fibril and matrix protein by changed prolidase, hydroxyproline, and antioxidant levels. Therefore, GJH subjects are followed up for JHS-associated problems. ${ }^{12,56}$

In conclusion, GJH was significantly reported in $57.1 \%$ of the study population, most of them are females. The incidence of GJH showed to be associated with poor physical activity, abnormal cellular oxidative stress, and collagen abnormalities measured by significant increase in change in cellular prolidase activity and hydroxyproline.

\section{Acknowledgments}

The authors are grateful to the Deanship of Scientific Research, King Saud University for funding through Vice Deanship of Scientific Research Chairs.

\section{Disclosure}

The authors declare that they have no conflicts of interest for this work.

\section{References}

1. Kirk JA, Ansell BM, Bywaters EG. The hypermobility syndrome. Musculoskeletal complaints associated with generalized joint hypermobility. Ann Rheum Dis. 1967;26(5):419-425. doi:10.1136/ ard.26.5.419

2. Jessee EF, Owen DS Jr, Sagar KB. The benign hypermobile joint syndrome. Arthritis Rheum. 1980;23(9):1053-1056. doi:10.1002/ art.1780230914

3. Klemp P, Stevens JE, Isaacs SA. Hypermobility study in ballet dancers. J Rheumatol. 1984;11(5):692-696.

4. Beighton P, De Paepe A, Steinmann B, Tsipouras P, Wenstrup RJ. Ehlers-danlos syndromes: revised nosology. Villefranche, 1997. Ehlers-Danlos National Foundation (USA) and Ehlers-Danlos Support Group (UK). Am J Med Genet. 1988;77(1):31-37. doi:10.1002/(SICI)1096-8628(19980428)77:1<31::AID-AJMG8>3.0. $\mathrm{CO} ; 2-\mathrm{O}$

5. Castori M, Tinkle B, Levy H, Grahame R, Malfait F, Hakim A. A framework for the classification of joint hypermobility and related conditions. Am J Med Genet C Semin Med Genet. 2017;175 (1):148-157. doi:10.1002/ajmg.c.31539

6. Scheper MC, Engelbert RH, Rameckers EA, Verbunt J, Remvig L, Juul-Kristensen B. Children with generalised joint hypermobility and musculoskeletal complaints: state of the art on diagnostics, clinical characteristics, and treatment. Biomed Res Int. 2013;2013:12105. doi:10.1155/2013/121054

7. Jansson A, Saartok T, Werner S, Renstrom P. General joint laxity in 1845 Swedish school children of different ages: age- and gender-specific distributions. Acta Paediatr. 2004;93(9):1202-1206. doi:10.1111/j.1651-2227.2004.tb02749.x

8. Lamari NM, Chueire AG, Cordeiro JA. Analysis of joint mobility patterns among preschool children. Sao Paulo Med J. 2005;12 (3):119-123. doi:10.1590/S1516-31802005000300006

9. Hasija RP, Khubchandani RP, Shenoi S. Joint hypermobility in Indian children. Clin Exp Rheumatol. 2008;26(1):146-150.

10. Clinch J, Deere K, Sayers A, et al. Epidemiology of generalized joint laxity (hypermobility) in fourteen-year-old children from the UK: a population-based evaluation. Arthritis Rheum. 2011;63 (9):2819-2827. doi:10.1002/art.30435

11. Abujam B, Aggarwal A. Hypermobility is related with musculoskeletal pain in Indian school-children. Clin Exp Rheumatol. 2014;32 (4):610-613.

12. Murray KJ. Hypermobility disorders in children and adolescents. Best Pract Res Clin Rheumatol. 2006;20(2):329-351. doi:10.1016/j. berh.2005.12.003

13. Grahame R. Joint hypermobility and genetic collagen disorders: are they related? Arch Dis Child. 1999;80(2):188-191. doi:10.1136/ adc.80.2.188 
14. Simmonds JV, Keer RJ. Hypermobility and the hypermobility syndrome. Man Ther. 2007;12(4):298-309. doi:10.1016/j. math.2007.05.001

15. Fikree A, Aziz Q, Grahame R. Joint hypermobility syndrome. Rheum Dis Clin N Am. 2013;39(2):419-430. doi:10.1016/j.rdc.2013.03.003

16. Kovacic K, Chelimsky TC, Sood MR, Simpson P, Nugent M, Chelimsky G. Joint hypermobility: a common association with complex functional gastrointestinal disorders. J Pediatr. 2014;165 (5):973-978. doi:10.1016/j.jpeds.2014.07.021

17. Marcolin ALV, Cardin SP, Magalhaes CS. Muscle strength assessment among children and adolescents with growing pains and joint hypermobility. Rev Bras Fisiot. 2009;13(2):110-115. doi:10.1590/ S1413-35552009005000006

18. Farmer AD, Fikree A, Aziz Q. Addressing the confounding role of joint hypermobility syndrome and gastrointestinal involvement in postural orthostatic tachycardia syndrome. Clin Autonom Res. 2014;24(3):157-158. doi:10.1007/s10286-014-0239-9

19. Nijs J, Meeus M, De Meirleir K. Chronic musculo skeletal pain in chronic fatigue syndrome: recent developments and therapeutic implications. Man Ther. 2006;11(3):187-191. doi:10.1016/j. math.2006.03.008

20. Erel O. A novel automated direct measurement method for total antioxidant capacity using a new generation, more stable ABTS radical cation. Clin Biochem. 2004;37(4):277-285. doi:10.1016/j. clinbiochem.2003.11.015

21. Erel O. A new automated colorimetric method for measuring total oxidant status. Clin Biochem. 2005;38(12):1103-1111. doi:10.1016/j. clinbiochem.2005.08.008

22. Lammers K, Lince SL, Spath MA, et al. Pelvic organ prolapsed and collagen-associated disorders. Int Urogynecol J. 2012;23(3):313-319. doi:10.1007/s00192-011-1532-y

23. Juul-Kristensen B, Kristensen JH, Frausing B, et al. Motor competence and physical activity in 8-year-old school children with generalized joint hypermobility. Pediatrics. 2009;124(5):1380-1387. doi:10.1542/peds.2009-0294

24. Kitchener RL, Grunden AM. Prolidase function in proline metabolism and its medical and biotechnological applications. J Appl Microbiol. 2012;113(2):233-247. doi:10.1111/j.13652672.2012.05310.x

25. Uçar D, Em S, Bozkurt M, et al. Serum prolidase activity in ankylosing spondylitis and rheumatoid arthritis. Clin Med Insights Arthritis Musculoskelet Disord. 2013;4:29-33.

26. Cakmak A, Zeyrek D, Atas A, Celik H, Aksoy N, Erel O. Serum prolidase activity and oxidative status in patients with bronchial asthma. J Clin Lab Anal. 2009;23(2):132-138. doi:10.1002/ jcla.20303

27. Cakmak A, Soker M, Koc A, Aksoy N. Prolidase activity and oxidative status in patients with thalassemia major. J Clin Lab Anal. 2010;24(1):6-11. doi:10.1002/jcla.20361

28. Moraes DA, Baptista CA, Crippa JA, Louzada-Junior P. Translation into Brazilian Portuguese and validation of the five-part questionnaire for identifying hypermobility. Rev Bras Reumatol. 2011;51(1):53-69. doi:10.1590/S0482-50042011000100005

29. Adib N, Davies K, Grahame R, Woo P, Murray KJ. Joint hypermobility syndrome in childhood. A not so benign multisystem disorder? Rheumatology (Oxford). 2005;44(6):744-750. doi:10.1093/rheumatology/keh557

30. Grahame R, Bird HA, Child A. The revised (Brighton 1998) criteria for the diagnosis of benign joint hypermobility syndrome (BJHS). J Rheumatol. 2000;27(7):1777-1779.

31. Beighton P, Solomon L, Soskolne CL. Articular mobility in an African population. Ann Rheum Dis. 1973;32(5):413-418. doi:10.1136/ard.32.5.413
32. Juul-Kristensen B, Rogind H, Jensen DV, Remvig L. Interexaminer reproducibility of tests and criteria for generalized joint hypermobility and benign joint hypermobility syndrome. Rheumatology (Oxford). 2007;46(12):1835-1841. doi:10.1093/rheumatology/ kem290

33. Cole TJ, Bellizzi MC, Flegal KM, Dietz WH. Establishing a standard definition for child overweight and obesity worldwide: international survey. $B r \quad$ Med $J$ 2000;320(7244):1-6. doi:10.1136/ bmj.320.7244.1240

34. Ashwel M, Lejeune S, McPherson K. Ratio of waist circumference to height may be better indicator of need for weight management. BMJ. 1996;312(7027):377. doi:10.1136/bmj.312.7027.377

35. Alghadir AH, Iqbal ZA, Gabr SA. Differences among Saudi and expatriate students: body composition indices, sitting time associated with media use and physical activity pattern. Int $J$ Environ Res Public Health. 2020;17(3):E832. doi:10.3390/ijerph17030832

36. Alghadir AH, Gabr SA, Al-Eisa ES. Effects of moderate aerobic exercise on cognitive abilities and redox state biomarkers in older adults. Oxid Med Cell Longev. 2016;2016:8. Article ID 2545168. doi:10.1155/2016/2545168.

37. Alghadir AH, Gabr SA, Anwer S, Al-Eisa E. Fatigue and oxidative stress response to physical activity in type 2 diabetic patients. Int J Diabetes Dev Ctries. 2016;36(1):59-64. doi:10.1007/s13410015-0420-2

38. Grant JA, Joseph AN, Campagna PD. The prediction of VO2max: a comparison of 7 indirect tests of aerobic power. J Strength Cond Res. 1999;13(4):346-352.

39. Bijur PE, Silver W, Gallagher EJ. Reliability of the visual analog scale for measurement of acute pain. Acad Emerg Med. 2001;8 (12):1153-1157. doi:10.1111/j.1553-2712.2001.tb01132.x

40. Todd KH, Funk KG, Funk JP, Bonacci R. Clinical significance of reported changes in pain severity. Ann Emerg Med. 1996;27 (4):485-489. doi:10.1016/S0196-0644(96)70238-X

41. Alghadir AH, Gabr SA. Efficacy of Rhus coriaria (sumac) juice in reducing muscle pain during aerobic exercise. Physiol Int. 2016;103 (2):231-242. doi:10.1556/036.103.2016.2.10

42. Şen V, Uluca Ü, Ece A, et al. Serum prolidase activity and oxidant-antioxidant status in children with chronic hepatitis B virus infection. Ital J Pediatr. 2014;40(1):95. doi:10.1186/s13052-0140095-1.

43. Tuna F. Prevalence of joint hypermobility, hypermobility spectrum disorder and hypermobile Ehlers-Danlos syndrome in a university population: an Observational Study. Eur Res J. 2020;6(2):120-129. doi:10.18621/eurj.466831

44. Kwon JW, Lee WJ, Park SB, Kim MJ, Jang SH, Choi CK. Generalized joint hypermobility in healthy female Koreans: prevalence and age-related differences. Ann Rehab Med. 2013;37 (6):832-838. doi:10.5535/arm.2013.37.6.832

45. Antonio DH, Magalhaes CS. Survey on joint hypermobility in university students aged 18-25 years old. Adv Rheumatol. 2018;58(1):3. doi:10.1186/s42358-018-0008-x

46. Tobias JH, Deere K, Palmer S, Clark EM, Clinch J. Joint hypermobility is a risk factor for musculoskeletal pain during adolescence: findings of a prospective cohort study. Arthritis Rheum. 2013;65 (4):1107-1115. doi:10.1002/art.37836

47. Sperotto F, Balzarin M, Parolin M, Monteforte N, Vittadello F, Zulian F. Joint hypermobility, growing pain and obesity are mutually exclusive as causes of musculoskeletal pain in schoolchildren. Clin Exp Rheumatol. 2014;32(1):131-136.

48. Hudson N, Fitzcharles MA, Cohen M, Starr MR, Esdaile JM. The association of soft-tissue rheumatism and hypermobility. $\mathrm{Br}$ $J$ Rheumatol. 1998;37(4):382-386. doi:10.1093/rheumatology/ 37.4.382 
49. McCormack M, Briggs J, Hakim A, Grahame R. Joint laxity and the benign joint hypermobility syndrome in student and professional ballet dancers. J Rheumatol. 2004;31(1):173-178.

50. Sanches SB, Oliveira GM, Osorio FL, Crippa JA, Martin-Santos R. Hypermobility and joint hypermobility syndrome in Brazilian students and teachers of ballet dance. Rheumatol Int. 2015;35 (4):741-747. doi:10.1007/s00296-014-3127-7

51. Engelbert RH, Bank RA, Sakkers RJ, Helders PJ, Beemer FA, Uiterwaal CS. Pediatric generalized joint hypermobility with and without musculoskeletal complaints: a localized or systemic disorder? Pediatrics. 2003;111(3):e248-e254. doi:10.1542/ peds.111.3.e248

52. Karna E, Surazynski A, Palka J. Collagen metabolism disturbances are accompanied by an increase in prolidase activity in lung carcinoma planoepitheliale. Int J Exp Pathol. 2000;81(5):341-347. doi:10.1046/j.1365-2613.2000.00168.x

53. Myara I, Myara A, Mangeot M, Fabre M, Charpentier C, Lemonnier A. Plasma prolidase activity: a possible index of collagen catabolism in chronic liver disease. Clin Chem. 1984;30(2):211-215. doi:10.1093/clinchem/30.2.211

54. Surazynski A, Miltyk W, Prokop I, Palka J. Prolidase-dependent regulation of TGF beta (corrected) and TGF beta receptor expressions in human skin fibroblasts. Eur J Pharmacol. 2010;649(13):115-119. doi:10.1016/j.ejphar.2010.09.034
55. Surazynski A, Miltyk W, Palka J, et al. Prolidase-dependent regulation of collagen biosynthesis. Amino Acids. 2008;35(4):731-738. doi:10.1007/s00726-008-0051-8

56. Palka JA, Phang JM. Prolidase activity in fibroblasts is regulated by interaction of extracellular matrix with cell surface integrin receptors. J Cell Biochem. 1997;67(2):166-175. doi:10.1002/(SICI)1097-4644(19971101)67:2<166::AID-JCB2>3.0.CO;2-V

57. Yazgan P, Geyikli I, Zeyrek D, et al. Is joint hypermobility important in prepubertal children? Rheumatol Int. 2008;28(5):445-451. doi:10.1007/s00296-008-0528-5

58. Altunoluk B, Efe E, Kurutas EB, et al. Elevation of both reactive oxygen species and antioxidant enzymes in vein tissue of infertile men with varicocele. Urol Int. 2012;88(1):102-106. doi:10.1159/ 000332156

59. Cevik M, Yazgan P, Aksoy N. Evaluation of antioxidative/oxidative status and prolidase parameters in cases of inguinal hernia with joint hypermobility syndrome. Hernia. 2014;18(6):849-853. doi:10.1007/ s10029-014-1224-x

\section{Publish your work in this journal}

The Journal of Pain Research is an international, peer reviewed, open access, online journal that welcomes laboratory and clinical findings in the fields of pain research and the prevention and management of pain. Original research, reviews, symposium reports, hypothesis formation and commentaries are all considered for publication. The manuscript management system is completely online and includes a very quick and fair peer-review system, which is all easy to use. Visit http:// www.dovepress.com/testimonials.php to read real quotes from published authors. 